\title{
Spawning time of two shallow-water brittle stars
}

\author{
Keryea Soong ${ }^{1, *}$, Yen-ju Lin ${ }^{1}$, Shyh-min $\mathrm{Chao}^{2}$, Dan Chang ${ }^{1}$ \\ ${ }^{1}$ Institute of Marine Biology and Kuroshio Research Group, Asia-Pacific Research Center, National Sun Yat-sen University, \\ Kaohsiung 804, Taiwan, ROC \\ ${ }^{2}$ National Museum of Natural Sciences, Taichung 400, Taiwan, ROC
}

\begin{abstract}
Broadcast spawning, wherein gametes of both sexes are released for external fertilization, is a common mode of reproduction in marine organisms. Despite its importance in the life histories of many species, discovery of its timing is often based on chance observations. Here we report on the spawning of 2 shallow-water brittle stars in southern Taiwan known to have spawning induction, i.e. ovary homogenates induce spawning of conspecific males. The gonad index of both species exhibited an annual cycle with peaks from mid-spring to early summer. Successful induction of spawning in male Ophiocoma scolopendrina (Lamarck) inhabiting the intertidal zone was limited to low tides. After manipulating the depth of the water inhabited by brittle stars, we discovered that successful induction of spawning was not sensitive to the actual water level. However, males could consistently be induced to spawn at the time of low tides even when deprived of tidal influences in the laboratory. Therefore, an endogenous clock mechanism entrained by tide-associated phenomena may control the inductivity of mature male $O$. scolopendrina. Time of the day, i.e. day versus night, had no effect in this species. In O. dentata (Müller and Troschel) living in the shallow subtidal zone in the same area, male induction was successful during both high and low tides and in both day and night.
\end{abstract}

KEY WORDS: Broadcast spawning - Sperm limitation · Spawn-induction · Biological rhythm • Brittle star · Predation avoidance Resale or republication not permitted without written consent of the publisher

\section{INTRODUCTION}

Broadcast spawning is difficult to observe in nature because the timing is often difficult to predict. Except for a few classic examples, such as a Japanese crinoid (Kubota 1980), the Palolo worm Palola viridis (Caspers 1984), and many reef corals (e.g. Harrison et al. 1984), in which the annual spawning time is well known and fairly predictable, relatively little information is available for other marine invertebrates. However, the timing of spawning is most likely correlated with environmental factors that may be critical for the survival of offspring or are simply used as cues to synchronize spawning (Morgan \& Christy 1994). Whereas the timing of spawning is often used to infer possible adaptive mechanisms, the proposed hypotheses are often difficult to test (e.g. Pearson \& Serrão 2006). Nevertheless, these hypotheses are helpful in providing directions when trying to determine the potential spawning time of a species.
The hypothesis of gamete dilution posits that a low fertilization rate is a severe challenge that limits the reproductive success of many organisms relying on external fertilization (Pennington 1985, Denny \& Shibata 1989). Adaptations solving the problem of dilution tend to increase encounter rates between sperm and eggs (Levitan \& Petersen 1995, Yund 2000). Synchronized gamete release within a population is thought to be one such solution (e.g. Harrison et al. 1984). On the other hand, spatial aggregation can help mobile species increase local densities, effectively shortening distances among individuals (Hagman \& Vize 2003). Pheromones are another mechanism for bringing together mature individuals or for triggering spawning when gametes of the opposite sex are detected or for directing the approach of sperm to eggs (e.g. Watson et al. 2003). One necessary result of synchronization by environmental factors or pheromones is that spawning times must be of short duration, making it less likely for spawning to be observed. 
Under the spawning-recruitment linkage hypothesis, recruitment may be the ultimate cause of the timing of spawning. This applies in species where settlement and recruitment are tightly linked to spawning and fertilization (Pearson \& Serrão 2006). Local, shortdistance, and high successful rates of recruitment are the goals of tightly synchronized spawning.

On the other hand, the predation avoidance hypothesis may apply in species for which spawning is a rare moment in their life histories and where swimming in the water column or appearing unprotected is essential for spawning individuals (e.g. Hagman \& Vize 2003). Reducing mortality rates during this dangerous act may be achieved by limiting spawning activity to times of low predation risk (Hendler \& Meyer 1982).

Knowledge of spawning time is useful both for practical and theoretical purposes. The natural spawning season is often considered the best opportunity for artificial propagation in controlled environments (e.g. Leu 1997). Seasons of natural recruitment supposedly follow that of natural spawning (e.g. Southworth \& Mann 2004), although the time elapsed may differ greatly between species. Being able to predict spawning time greatly improves our ability to manage these species. By identifying the specific conditions under which natural spawning occurs, we may understand the proximate cues used and the types of selection shaping life histories (see Yund 2000).

Shallow waters, especially intertidal zones, are characterized by fluctuations in environmental factors. Besides light-dark alternations, water immersion cycles also cause rhythmic environmental changes, e.g. temperature, desiccation, and noise (Neumann 1987). These fluctuations exert great influence on the performance and mortality of organisms living in these habitats (e.g. Taylor 1999). Endogenous rhythms controlling the behavior of organisms, including spawning activities, are certainly likely adaptations to these fluctuations (e.g. Palmer 2000).

It is possible to determine the natural spawning time of invertebrate populations by periodically monitoring changes in their reproductive organs or calculating gonad indices (e.g. Hendler 1979). However, the temporal resolution of this approach is not always satisfactory. For example, histological studies of common Caribbean reef corals narrowed down their reproductive seasons to within 1 to 2 mo (Soong 1991), but the actual spawning of each species was observed to take place within a $1 \mathrm{~h}$ period (Van Veghel 1994). Direct observation in the field provides good evidence of natural spawning events, but systematic observation requires significant time and resources (see Harrison et al. 1984, Himmelman et al. 2008). Even in the intertidal zone, the most accessible marine environment, knowledge of a species' spawning times is often based on sporadic observations or indirect inferences from experiments (Marshall 2002, Pearson et al. 2004).

Two shallow-water brittle stars, Ophiocoma scolopendrina (Lamarck) and O. dentata (Müller and Troschel), in southern Taiwan have evolved spawninducing pheromones. Males of both species can be induced to spawn when exposed to a homogenate of conspecific ovaries (Soong et al. 2005). However, it is unclear whether other mechanisms are involved in spawning to increase reproductive success. Since males of these 2 brittle stars can be induced to spawn by exposure to ovary homogenates released by females, differences in inductivity under controlled conditions may correspond to differences of spawning time in nature. Here, we tested the roles of tide, light, water level, and biological clocks on the induction of spawning in $O$. scolopendrina and $O$. dentata males.

\section{MATERIALS AND METHODS}

The study site at Wanliton $\left(22^{\circ} 00^{\prime} \mathrm{N}, 120^{\circ} 42^{\prime} \mathrm{E}\right)$, southern Taiwan, is characterized by reef flats in the upper parts of the fringing reefs. Ophiocoma scolopendrina were found in the crevices in shallow intertidal pools that were protected from wave exposure at low tides, and $O$. dentata were found under the scattered slabs and boulders in the subtidal channels cutting into reefs (Applegate 1984).

The local tide pattern is a mixture of diurnal, semidiurnal, and mixed tides with each representing 19, 6, and $75 \%$ of the tidal cycles between April and June 2007. All times of high and low tides in this investigation were based on the local tide table (Central Weather Bureau 2006).

Spawning season. To determine the reproductive seasons of the brittle stars, 12 to 22 individuals of each species were collected monthly between June 1997 and July 1998. The gonad index, i.e. (gonad weight/ total disc weight) $\times 100 \%$, was used to follow the reproductive status of these brittle stars. The specimens were fixed in $10 \%$ neutral formalin and then preserved in $70 \%$ ethyl alcohol. Gonads and discs of preserved specimens were weighed using an electronic balance (A \& D Weighing) fter dissection and blotting dry. Since gonad color could be used to distinguish gender only when the gonads were large, gonad indices of the 2 sexes were pooled to show seasonal patterns.

Standard spawning test. To test for the spawning response in males, an ovary homogenate was prepared from isolated gonads of ripe females by mixing at a ratio of $1 \mathrm{~g}$ of ovaries to $100 \mathrm{ml}$ sea water. The homogenate was prepared prior to each test by grinding ovaries dissected from several females either in glass grinders 
or a rotor homogenizer and then diluting to the 1:100 ratio. The homogenates were kept cool before use. Our other tests (K. Soong et al. unpublished) indicated that the active ingredient remains intact after boiling, extraction, and storage in refrigeration for 1 yr. Mature males can be identified by the white gonads revealed through slits between the discs and the arms. A male was placed in a partly filled $(\sim 300 \mathrm{ml}) 1 \mathrm{l}$ beaker of seawater at ambient temperature. When $2 \mathrm{ml}$ of the homogenate were added to the beaker, inducible males usually spawned within seconds. Non-spawning males either conspicuously pumped their discs without releasing semen or showed no response. Males were never induced to spawn when exposed to ovary homogenates of other species (Soong et al. 2005).

Tidal and diel patterns. To test the effect of tides on induction, male Ophiocoma scolopendrina were collected at low and high tides, respectively, and immediately subjected to the standard spawning test on shore. This experiment took place when both tides occurred in the daytime from 27 to 28 July 2005.

An additional experiment was conducted over a $24 \mathrm{~h}$ period to look for a possible diel pattern when individuals were collected and tested at low and high tides in both day and night. This was also done on shore, from 10 to 11 August 2005.

Water level versus tidal status. This experiment tested whether spawning of male Ophiocoma scolopendrina was dependent on the water level or on the tidal cycle. We collected 100 males, keeping 25 males in each of 4 cages in situ on the reef flat. One hour before high tide, a cage of male brittle stars was moved to a deep pool within the intertidal zone; a second cage was moved in the opposite direction to shallower water than the depth on the reef flat. The difference in depth between the 2 cages was about $1 \mathrm{~m}$. In the study area, the difference between extreme high and extreme low water at spring tide is about $1 \mathrm{~m}$ (Central Weather Bureau 2006). At high tide $1 \mathrm{~h}$ later, we individually tested each male's response to ovary homogenate using the standard spawning tests at the collection site. We repeated this procedure, i.e. moving the other 2 cages to the same deep and shallow spots, and $1 \mathrm{~h}$ later testing each individual, but at the time of low tide. In this experiment, both tests, 1 at high tide, 1 at low tide, took place in the daytime of 19 August 2005.

Biological clock involvement. To test whether an endogenous biological clock was involved in the induction of spawning in male Ophiocoma scolopendrina and $O$. dentata, we tested whether they could be induced only at certain tides even though there was no tide information available to them. About 50 males of each species were transported to the laboratory about $8 \mathrm{~km}$ away. These males were kept individually in numbered beakers in an outdoor, shaded tank that had flowing seawater under ambient temperature and light conditions. The water level was kept constant, i.e. no tidal level changes could be detected by the brittle stars. Beginning $10 \mathrm{~h}$ after capture, each male was tested for spawning at the time of both high and low tide for 2 consecutive days, i.e. in total, 8 standard tests were conducted on each male. After each test, the water in each beaker was replaced with fresh seawater before returning to the holding tank. In this experiment, half of all males started their first test at high tide and the other half started at low tide. In the statistical analysis, males that had at least 1 spawning event out of the 4 tests administered were defined as spawning males at the particular tidal phases ( 2 tidal phases: high and low), during the $2 \mathrm{~d}$ period. The tests for $O$. dentata were run from 30 to 31 March, whereas those for O. scolopendrina were run from 10 to 12 May 2006.

The possible effect of light on induction of spawning of Ophiocoma dentata males was not tested, since this species was inducible to spawn both in daylight and at night (Soong et al. 2005).

The behavior of pumping the disc without releasing semen was noticed in experiments toward the end of the reproductive season in 2005. The pumping behavior is obviously a response to egg homogenate, and it is similar to spawning both in action and in timing. In statistical tests, this behavior was either pooled with 'spawning' or excluded, but it was never pooled with 'no response.' In no case did the pooling or exclusion make a difference in the conclusions. Fisher's exact tests were used in all analyses of contingency tables.

\section{RESULTS}

Spawning season. Both species of brittle stars had annual reproductive cycles as indicated by the changes in their gonad indices (Figs. 1 \& 2). In Ophiocoma dentata, the gonad index reached high level of $>30 \%$ in July 1997 and April 1998. In O. scolopendrina, the gonad index reached about $25 \%$ in April and May 1998 (Fig. 1). Males of both species were successfully induced to spawn during seasons of high gonad indices.

Tidal and diel patterns. In the test of the effects of tide, 27 of 50 Ophiocoma scolopendrina males were induced to spawn at low tide; 14 males pumped their discs without releasing semen at this time. On the other hand, only 1 of 25 males was induced to spawn at high tide. The dependence of the responses of the brittle stars to tide was significant ( $\mathrm{p}<0.01$, Fisher's exact test; Fig. 2). The conclusions of all our experiments were not affected by the pooling.

In the experiment investigating diel patterns of inductivity of male Ophiocoma scolopendrina, time of 


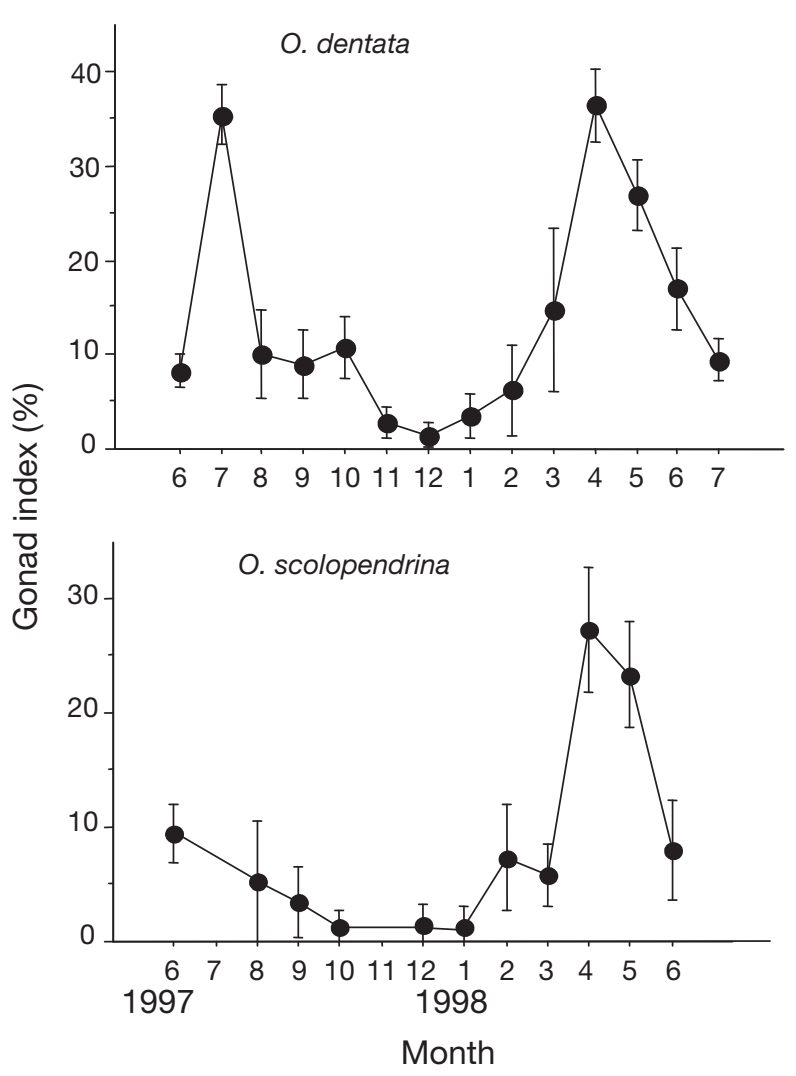

Fig. 1. Ophiocoma dentata and O. scolopendrina. Change in gonad index from June 1997 to July 1998. Error bars indicate $95 \%$ confidence intervals; sample sizes were between 12 and

22 in each month and higher between March and June

the day did not affect inductivity at either low tide $(\mathrm{p}=$ $0.71, \mathrm{n}=122)$ or at high tide $(\mathrm{p}=0.33, \mathrm{n}=75$, Fisher's exact tests; Fig. 3). In this experiment, we conducted 4 tests within $24 \mathrm{~h}$, demonstrating that the brittle stars were inducible at both low tides, but showed no response at both high tides of the day. This experiment was done toward the end of the reproductive season in August 2005, when there was an overall low rate $(11 \%$ at low tide) of successful spawning induction.

Water level versus tidal status. All male Ophiocoma scolopendrina spawned only at low tide in this experiment on shore. Individuals pumping discs were observed only at low tide. Water level had no effect on inductivity regardless of whether 'pumping disc' was pooled with 'spawning' or omitted from the analyses (Fisher's exact tests; Fig. 4). We did not test the effect of water level on spawning of $O$. dentata, since high proportions of individual males spawn at either low or high tide (see next section).

Biological clock involvement. In the laboratory experiment with 8 standard tests on each individual, spawning of male Ophiocoma scolopendrina and $O$. dentata was dependent on the tides (Fisher's exact tests: $\mathrm{p}<0.01$ and $\mathrm{p}=0.05$, respectively; Fig. 5), even

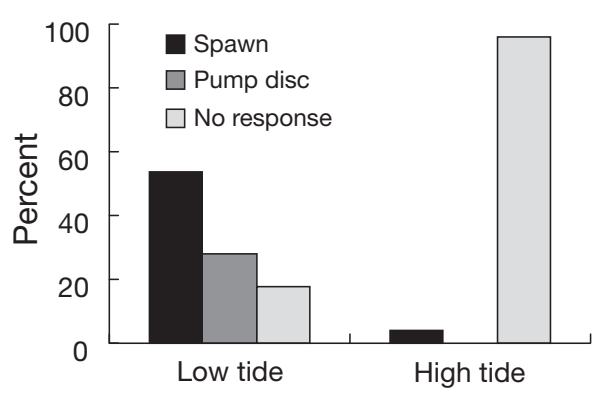

Fig. 2. Ophiocoma scolopendrina. Response frequencies of males to conspecific ovary homogenates at low and high tides. Tests of independence between male responses and tidal status, $\mathrm{p}<0.01$, Fisher's exact test, regardless of whether 'Pump disc' was pooled with 'Spawn' or omitted from the analysis. $\mathrm{N}=50$ (low tide) and 25 (high tide)

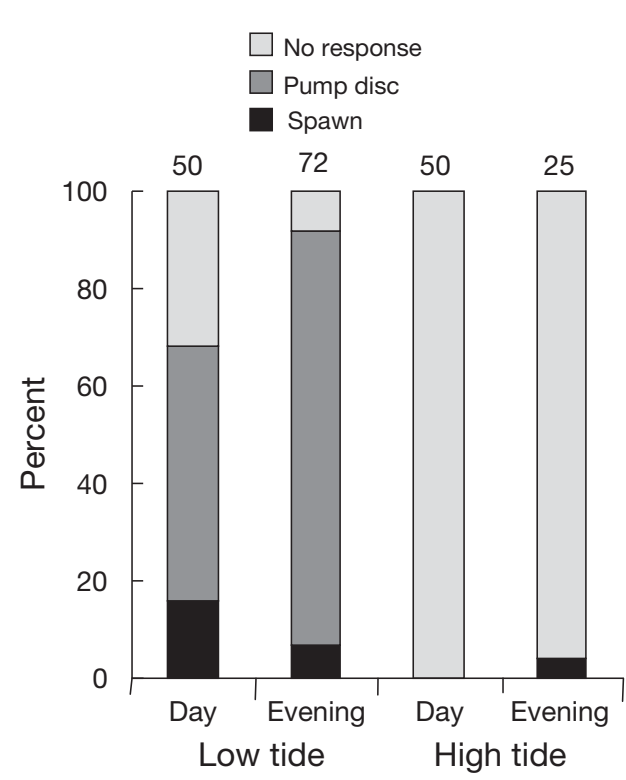

Fig. 3. Ophiocoma scolopendrina. Response frequencies of males to conspecific ovary homogenates tested in the day and in the evening, at low and high tides. Tests of independence between male responses and Day/Evening, $\mathrm{p}=0.71,0.33$ (Fisher's exact test) for low and high tides, respectively, when 'Spawn' and 'Pump disc' were pooled as responsive. Sample sizes indicated above bars

though there was no change in water level throughout the period. For $O$. scolopendrina, 22 of 48 males spawned at least once during 1 of the low tides, but only 1 of 48 spawned at any high tide. Eleven spawning events occurred in the second to fourth low tides after transfer into the laboratory.

Of 54 male Ophiocoma dentata, 34 (63\%) were induced to spawn in at least 1 low tide and 23 (43\%) spawned in at least 1 high tide. Some individual males spawned only at high tide and some spawned only at low tide. However, 17 males $(31 \%)$ spawned at both 


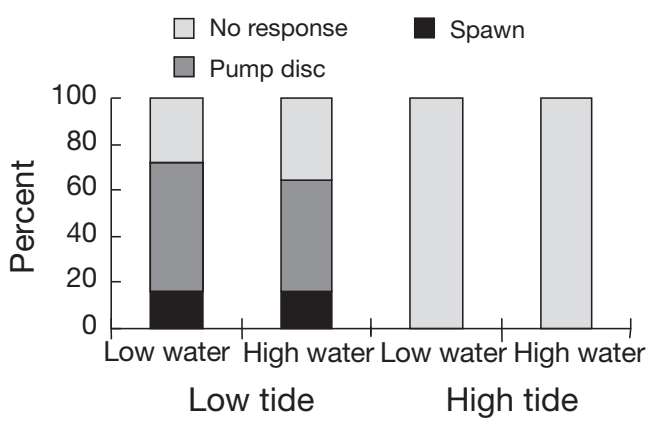

Fig. 4. Ophiocoma scolopendrina. Response frequencies of males to conspecific ovary homogenates at different water levels, at low and high tides. Tests of independence between male responses and water level, $p>0.99, p=0.76$ whether 'Pump disc', respectively, was pooled with 'Spawn' as responsive or omitted at low tide; $\mathrm{p}>0.99$ at high tide, Fisher's exact tests. $\mathrm{N}=25$ in each of 4 cases

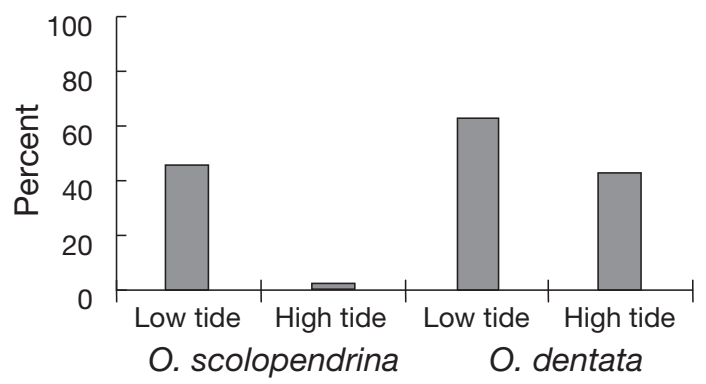

Fig. 5. Ophiocoma scolopendrina and O. dentata. Response frequencies of spawning males to conspecific ovary homogenates under constant water levels in the laboratory. Tests of independence between male response and tide, $\mathrm{p}<0.01, \mathrm{p}=$ 0.05 (Fisher's exact tests) for O. scolopendrina and O. dentata, respectively. Spawning males in this analysis were defined as those that showed at least 1 spawning response out of the 4 tests administered at the indicated tidal phase during the $2 \mathrm{~d}$ period

high and low tides, and 14 males (25\%) did not spawn at all. At the individual level, no dependence was found between the occurrence of spawning at high and at low tides $(\mathrm{p}=0.17$, Fisher's exact test).

\section{DISCUSSION}

Our results strongly suggest that the 2 congeneric brittle stars spawn under different environmental conditions. Successful induction of spawning in males of the intertidal brittle star Ophiocoma scolopendrina was related to tidal status, and this may well be controlled through an endogenous clock mechanism; on the other hand, the subtidal $O$. dentata was less sensitive to tides (Figs. 2 to 5).
At low tides, the tidal pools had much less water and probably had reduced flow rates. Therefore, the adaptive mechanisms working at this time must be connected to such environmental factors. Predatoravoidance may be one such underlying adaptive mechanism of spawning at low tide. Frequency of arms undergoing regeneration in Ophiocoma scolopendrina is high in similar habitats on a nearby offshore island, Hsiao-Liu-Chiu (Soong et al. 1997). Moreover, since O. scolopendrina males rush out of their crevices to approach released egg homogenates (Lin 2006), they may attract predators and suffer higher injury and mortality rates at this time. At low tide, most $O$. scolopendrina were in very shallow water (also see Oak \& Scheibling 2006); thus there is little space for predators in the water column. On the other hand, limiting spawning to evenings should also effectively lower predation loss from predators relying primarily on visual cues. In fact, earlier sightings of brittle star spawning in subtidal habitats were mostly in the evenings (Hendler 1991, Hagman \& Vize 2003). A recent investigation, however, reported 2 daytime spawning ophiuroids (Himmelman et al. 2008). Our experiments showed that $O$. scolopendrina males could be induced to spawn regardless of whether it was day or night, as long as the tide was low (Fig. 3). It is possible that limiting the spawning time to low tide has effectively eased the predation pressure for the species such that further restricting it to the evening is not necessary.

The settlement and recruitment hypothesis (Pearson \& Serrão 2006) is unlikely to explain low-tide spawning in Ophiocoma scolopendrina (or O. dentata). This is because brittle star larvae are planktonic for a relatively long time (Podolsky \& McAlister 2005). Thus, little correlation is expected between tide-related spawning and the eventual settlement of the planktonic larvae.

Tide-related reproductive activities have been reported in other intertidal organisms (e.g. Palmer 2000). Many investigators have suggested sperm limitation as an ultimate cause for species with external fertilization (e.g. Marshall 2002). Besides a limited amount of water to dilute sperm, the extent of water agitation may be another factor, since the habitat at the collection site is isolated from wave action at low tide. Both of these factors suggest that high sperm concentrations could be maintained for a significantly longer period than if spawning occurs at other times. In other words, the sperm-limitation hypothesis remains viable to explain the spawning time of Ophiocoma scolopendrina.

In the subtidal Ophiocoma dentata, however, a high proportion of males could be induced to spawn at both high and low tides (Fig. 5). Since O. dentata inhabits 
the gaps under slabs and boulders, the amount of water in the gaps remains unchanged as tide level changes. Thus, restricting spawning to low tide may not help increase fertilization rates. Unlike $O$. scolopendrina, male $O$. dentata did not approach conspecific ovary homogenates, even though these homogenates induced them to spawn (Lin 2006). Therefore, male $O$. dentata do not necessarily increase exposure to predators at spawning. This eliminates the need to avoid predators by restricting spawning activity to a certain time of the day. In other words, the trait of being inducible to spawn at both high and low tides in $O$. dentata is compatible with the predictions of both the predator-avoidance and the sperm-dilution hypotheses.

Both brittle star species had relatively long natural spawning seasons, but the ability of males to spawn repeatedly is limited (Soong et al. 2005). Thus, the brittle stars should benefit by choosing a favorable condition under which to spawn. The low tide is just one such condition we found for Ophiocoma scolopendrina. In other brittle stars, abrupt temperature changes have been implicated (Himmelman et al. 2008). The results of our water-level experiment (Fig. 4) further suggest that the water level is not the direct proximate factor. Rather, it is likely that the tidal level is an entraining factor of an endogenous biological clock which in turn controls spawning events in $O$. scolopendrina. This hypothesis is supported by the fact that when male $O$. scolopendrina were kept in the laboratory without water level fluctuations, they were still inducible only at low tides (Fig. 5).

Having spawning controlled by an endogenous clock confers several possible advantages. Presumably, it improves synchrony between the behavior of organisms and the environment (Saunders 2002). This may be important in the intertidal zone where water level fluctuates over both the short (wave) and long (tide) term. Brittle stars should spawn only during low tide, when the water level remains low for an extended period. Endogenous clocks can also improve synchrony among individuals and sexes since they are entrained by the same environmental factors. Although spawning itself seems to take only seconds, preparation and readiness for spawning involve complicated changes in physiology (see Olive 1995). A clock-mediated mechanism can ensure that mature brittle stars are ready to spawn when the tides are right.

The positive response of males to ovary homogenate at both low tides of the day (Fig. 3) suggests a proximate cue associated with the semidiurnal tide pattern. The 2 low tides each day may each entrain an endogenous clock of an intertidal organism, i.e. there are 2 tide-entrained endogenous clocks (see Palmer 2000).
At Wanliton, low water may occur once or twice a day, and there is an intermediate situation, e.g. at neap tide, when the high-low tides are much reduced in magnitude. Obviously, tidal time is not a perfect indicator of absolute water level in the study area. If the extent of sperm dilution or predation pressure is directly related to water level, then spawning at higher low tides could not effectively address these challenges. Eliminating all other times of the day as inappropriate for spawning may be enough improvement to tolerate the costs of spawning at the less optimal low tides.

We have yet to succeed in inducing female Ophiocoma scolopendrina to spawn. However, they must also release eggs at low tide. Since successful fertilization depends on male responses, any female releasing eggs at high tides would produce few, if any, fertilized eggs. By inferring from the difference discovered between these 2 congeneric species of brittle stars living close by, it is clear that the timing of spawning is critical in the evolution of these broadcast spawning species.

Acknowledgements. We thank the late Dr. M. H. Chen for providing laboratory space in the National Museum of Marine Biology \& Aquarium (Taiwan), and B. N. Chen, M. H. Chen, I. H. Chang, D. K. Wang, I. H. Lin, W. Y. Yeh, and H. Y. Yu for volunteering to help in the field, 4 anonymous reviewers and Dr. C. L. Bridgman for many helpful comments on an early version of the manuscript, and R. Haesevolts for English editing. This research was partly supported by grants from the National Science Council to K.S., and the Ministry of Education, Taiwan, to the Kuroshio Research Group, Asia-Pacific Ocean Research Center, National Sun Yat-Sen University.

\section{LITERATURE CITED}

Applegate AL (1984) Echinoderms of southern Taiwan. Bull Inst Zool Acad Sin 23:93-118

Caspers H (1984) Spawning periodicity and habitat of the Palolo worm Eunice viridis in the Samoan Islands. Mar Biol 79:229-236

Central Weather Bureau (2006) Tide tables 2007. Central Weather Bureau, Taiwan

> Denny MW, Shibata MF (1989) Consequence of surf-zone turbulence for settlement and external fertilization. Am Nat 134:859-889

Hagman DK, Vize PD (2003) Mass spawning by two brittle star species, Ophioderma rubicundum and O. squamosissimum (Echinodermata: Ophiuroidea), at the Flower Garden Banks, Gulf of Mexico. Bull Mar Sci 72:871-876

Harrison PL, Babcock RC, Bull GD, Oliver JK, Wallace CC, Willis BL (1984) Mass spawning in tropical reef corals. Science 223:1186-1189

Hendler G (1979) Reproductive periodicity of ophiuroids (Echinodermata: Ophiuroidea) on the Atlantic and Pacific coasts of Panama. In: Stancyk SE (ed) Reproductive ecology of marine invertebrates. University of South Carolina Press, Columbia, SC, p 145-156

Hendler G (1991) Echinodermata: Ophiuroidea. In: Giese AC, Pearse JS (eds) Reproduction of marine invertebrates, Vol VI. Echinoderms and lophophorates. Boxwood Press, 
Pacific Grove, CA, p 355-511

Hendler G, Meyer DL (1982) Ophiuroids flagrante delicto and notes on the spawning behavior of other echinoderms in their natural habitats. Bull Mar Sci 32:600-607

Himmelman JH, Dumont CP, Gaymer CF, Vallieres C, Drolet D (2008) Spawning synchrony and aggregative behaviour of cold-water echinoderms during multi-species mass spawnings. Mar Ecol Prog Ser 361:161-168

Kubota H (1980) Synchronization of spawning in the crinoid, Comanthus japonica. In: Clark WH, Adams TS (eds) Advances in invertebrate reproduction. Elsevier, Amsterdam, p 69-74

Leu MY (1997) Natural spawning and mass larviculture of black porgy Acanthopagrus schlegeli in captivity in Taiwan. J World Aquacult Soc 28:180-187

Levitan DR, Petersen C (1995) Sperm limitation in the sea. Trends Ecol Evol 10:228-231

Lin YJ (2006) The spatial and temporal adaptations at spawning of two brittlestars. MSc thesis, National Sun Yat-sen University, Kaohsiung

Marshall DJ (2002) In situ measures of spawning synchrony and fertilization success in an intertidal, free-spawning invertebrate. Mar Ecol Prog Ser 236:113-119

Morgan SG, Christy JH (1994) Plasticity, constraint, and optimality in reproductive timing. Ecology 75:2185-2203

Neumann D (1987) Tidal and lunar rhythmic adaptations of reproductive activities in invertebrate species. In: Pévet $P$ (ed) 8th ESCP Conf, Comparative Physiology of Environmental Adaptations. Karger, Basel, p 152-170

Oak T, Scheibling RE (2006) Tidal activity pattern and feeding behaviour of the ophiuroid Ophiocoma scolopendrina on a Kenyan reef flat. Coral Reefs 25:213-222

Olive PJW (1995) Annual breeding cycles in marine invertebrates and environmental temperature: probing the proximate and ultimate causes of reproductive synchrony. J Therm Biol 20:79-90

Palmer JD (2000) The clocks controlling the tide-associated rhythms of intertidal animals. Bioessays 22:32-37

Pearson GA, Serrão EA (2006) Revisiting synchronous gamete

Editorial responsibility: Don Levitan,

Tallahassee, Florida, USA release by fucoid algae in the intertidal zone: fertilization success and beyond? Integr Comp Biol 46:587-597

Pearson GA, Serrão EA, Dring M, Schmid R (2004) Blue- and green-light signals for gamete release in the brown alga, Silvetia compressa. Oecologia 138:193-201

Pennington JT (1985) The ecology of fertilization of echinoid eggs: the consequences of sperm dilution, adult aggregation, and synchronous spawning. Biol Bull 169:417-430

Podolsky RD, McAlister JS (2005) Developmental plasticity in Macrophiothrix brittlestars: Are morphologically convergent larvae also convergently plastic? Biol Bull 209: $127-138$

Saunders DS (2002) Insect clocks. Elsevier, Amsterdam

Soong K (1991) Sexual reproductive patterns of shallowwater reef corals in Panama. Bull Mar Sci 49:832-846

Soong K, Shen Y, Tseng SH, Chen CP (1997) Regeneration and potential functional differentiation of arms in brittlestar, Ophiocoma scolopendrina (Lamarck) (Echinodermata: Ophiuroidea). Zool Stud 36:90-97

> Soong K, Chang D, Chao SM (2005) Presence of spawninducing pheromones in two brittle stars (Echinodermata: Ophiuroidea). Mar Ecol Prog Ser 292:195-201

Southworth M, Mann R (2004) Decadal scale changes in seasonal patterns of oyster recruitment in the Virginia sub estuaries of the Chesapeake Bay. J Shellfish Res 23: 391-402

Taylor MH (1999) A suite of adaptations for intertidal spawning. Am Zool 39:313-320

> Van Veghel MLJ (1994) Reproductive characteristics of the polymorphic Caribbean reef building coral Montastrea annularis. I. Gametogenesis and spawning behavior. Mar Ecol Prog Ser 109:209-219

Watson GJ, Bentley MG, Gaudron SM, Hardege JD (2003) The role of chemical signals in the spawning induction of polychaete worms and other marine invertebrates. J Exp Mar Biol Ecol 294:169-187

Yund PO (2000) How severe is sperm limitation in natural populations of marine free-spawners? Trends Ecol Evol 15:10-13

Submitted: February 4, 2008; Accepted: October 28, 2008

Proofs received from author(s): January 23, 2009 